\title{
INFLUENCE OF VISUAL INTEGRATION AND PEDESTRIAN MOBILITY ON EVERYDAY EXPERIENCE OF PUBLIC SPACE
}

DOI: $10.18485 /$ arh_pt.2020.7.ch7

\section{_ Stefan Škorić}

University of Novi Sad, Faculty of Technical Sciences, Department of Architecture and Urban Planning, Trg Dositeja Obradovica 6, stefan.skoric@uns.ac.rs

\section{Aleksandra Milinković \\ University of Novi Sad, Faculty of Technical Sciences, Department of Architecture and Urban Planning, Trg Dositeja Obradovica 6, a.milinkovic@uns.ac.rs}

\section{_ Dijana Brkljač}

University of Novi Sad, Faculty of Technical Sciences, Department of Architecture and Urban Planning, Trg Dositeja Obradovica 6, dijana.brkljac@uns.ac.rs

\section{_ Milena Krklješ}

Professor, Ph.D, University of Novi Sad, Faculty of Technical Sciences, Department of Architecture and Urban Planning, Trg Dositeja Obradovica 6, m.krkljes@uns.ac.rs

\begin{abstract}
During the previous decades, non-implementation of legal regulations has led to unrestrained arrangement of inadequate physical and visual obstacles that have induced great negative effect on the pedestrian mobility and visibility at the public spaces of Novi Sad (Serbia). On the other hand, visual integration and effectiveness of mobility at the visited public space can induce a positive or negative effect on the visitors' perception of that space, which represents valuable input factor for further analysis. Therefore, a space syntax methodology is used in order to comprehend complex links between morphological and spatial characteristics of built environment and pedestrian movement and visibility at the selected public spaces in Novi Sad, by applying visibility graph analysis (VGA). The study is based on analyses of how are all fragments of public space visually interconnected, and what is its relation to the pedestrian movement and usage of public space. The analysis is done both at the ground level and at the eye level, with the focus on fixed and mobile physical and visual barriers. Obstacles are grouped into different categories, with the focus on immovable public furniture and moveable furniture of private cafes and restaurants that have particularly discouraged people from moving freely around public space with greater selection of walking routes. Improved visual integration of space and unobstructed pedestrian mobility are reassessed with the aim of promoting walking without interruptions and impediments, and as a starting point for other public activities.
\end{abstract}

KEYWORDS _ public space, mobility, visibility, obstacles, Novi Sad

\section{INTRODUCTION}

Urban space is a domain that arises through a symbiotic action between physical space, sensory experience, and user activities that takes place in that location (Montgomery, 2007: 269). The urban 
environment with its form, morphology, traffic, and other aspects, influences various ways of the public space usage in terms of frequency, function, accessibility, mobility, etc. The structure of urban matrix is the most important determinant of urban movement (Stupar, 2009: 96), which makes the parts of the city adapted to pedestrian traffic very different from all others due to design which is adapted to the speed of a person moving about $5 \mathrm{~km} / \mathrm{h}$. Walking as a sustainable form of transport (Đukić and Vukmirović, 2011) is a significant motivator for organizing and branding of public spaces, thus positively influencing the environmental, functional and psycho-physical aspects of space and its users.

In accordance with the speed of pedestrian movement, walking as a mechanical action allows the person to activate the sensory apparatus, and adaptation to pedestrian movement leaves the possibility for optimal understanding of the environment and events in the immediate vicinity. The connection that happens between man and city, and with other people, is based on an individual experience that is subjective, and the activation of sight, smell, hearing, touch, taste and sound is more intense due to the multitude of indicators of these sensory reactions that exist in the public space. Pedestrian-friendly distances in both sensory and physical terms are adapted to the sense of space, suggesting that human scale is the primary reference of those spaces. According to Montgomery (1998: 97), this statement is confirmed through the claim that "urban quality must be considered in much broader terms than the physical attributes of buildings, spaces and street patterns", because it is also influenced by architectural form, scale, landmarks, vistas, meeting places, open spaces, greenery, etc.

Public space with urban integrity is extremely important for city marketing, branding and the image of a city presented through its exploitation (Škorić, et al., 2016). The need to visit such places and make users feel safe, satisfied and fulfilled (Speck, 2013: 11) is expressed in the urban policy of each settlement. Such places are pedestrian areas and old parts of the city that bring together the largest number of users and spaces that meet the criteria of hybridity, connectivity, porosity, authenticity, vulnerability (Elin, 2006: 9), which Elin defines as fundamental in evaluating the quality of places. Furthermore, the issue of walking is related to the horizontal and vertical spatial levels and the possibilities for viewing them. Horizontal level is the key domain in which the most intense contacts, offers and diversity of elements are concerned, as well as the area on which the pedestrian moves, uses the ground floors of buildings, exploits urban furniture, meets up with other people who are also active users of space, etc. On the other hand, the vertical level represents an extremely significant spatial extent, a physical boundary that closes the pedestrian viewing field, and serves as a landmark, scenery or motive and goal of movement.

\section{STAYING ON THE PUBLIC SPACE AND PUBLIC ACTIVITIES}

According to comprehensive research done by Jan Gehl, conducted on the topics of urban relations, users and the quality of the place, it is concluded that the key motives that lead users to an area are: easy transition between public and private spaces, the ability to see what is happening, a short and convenient route, movement motivation, the need to go somewhere, and the need to do something (Gehl, 2013: 113-120). Being in a public space accordingly gains pronounced social benefits, economic, cultural, and other characteristics that determine a person as a social being and affect everyday quality of life. In spatial contact with other people, an individual can only collect information about them, through a brief observation of the environment and events, which is an uncontrolled interaction established among visitors to the space. Conversely, if controlled interaction is viewed, it will be found that relationships among actors in space can be conditioned by the creation of focus or events to which many users are directed, and among them, there is a closeness resulting from gathering around the same landmark (Goffman, 1966: 24). Goffman states that such focused and controlled activities, due to human contact and based on interests and personal affinities create individual attention, while the focus on the event itself is conditioned by the number of participants in the event. 
Outdoor activities can further be defined as necessary, optional and social activities (Gehl, 2010: 9-12), and their frequent occurrence depends on where they are established, the quality of the environment and user comfort, favourable external influences, desire, mood and need of the user. Each individual participating in the event, on that occasion, develops and meets personal needs and by their wishes directly or indirectly influences the course, intensity or frequency of the same. By type, an activity that is established in a public space can be:

- passive - the person as the actor of the event is present, does not participate, does not contribute, is not interested in the event or events and is absent;

_ half-passive - a person just watches, listens, buys, and has no communication with anyone;

- semi-active - the person observes the activity, but is himself active in some way;

_ active - the man is the actor of the event. (Milinković, 2019: 79)

\section{PHYSICAL AND VISUAL OBSTACLES ON PUBLIC SPACES}

Relations between people are basic aspects of public spaces in terms of socialization and their initiation or avoidance is conditioned by spatial relations, organization of the place where the event is established, placement of equipment, obstacles, movement trajectory, etc. Basically, walking is a linear movement that brings the walker from one place to another, but figuratively, it is also a prospective start for many other public activities. One of the requirements for a comfortable walk is a free and undisturbed movement, without frequent interruptions and obstacles. Obstruction in space can be primarily designed and planned, while there are those that are conditioned by the need for safety, lighting, rest, etc. According to significant influential aspects in the public space, obstacles may be:

A. in relation to type: physical or sensual (senses of vision, hearing, smell, and touch);

B. in relation to mobility: fixed or mobile (permanently set, periodically present).

Each of the obstacles in the public space is characterized by its purpose according to which their exploitation and placement is possible, so that the flow and direction of movement is predesigned in some space. Therefore, the most common obstacles in public areas are: elements of street furniture, elements of urban equipment and signalling, equipment of cafes and restaurants, denivelation of space, enclosure of space, elements for security and protection, etc.

By moving through public space, the user needs to feel comfortable, to look at the environment and changes in urban space, to anticipate events, unexpected situations, and focus their attention on things that sensory receptors recognize as dynamic and interesting. Visual integration of public space is important, as "if people do not see a space, they will not use it" (Whyte, 1980: 58). Viewing is thus differentiated into three spatial levels which are: at the ground floor level, at the eye level and above the eye level (Gehl, 2011). It is important to note that spaces that are more difficult to access are rarely used by humans. Accessibility and visibility are important but not decisive factors in urban exploitation, since in pedestrian zones the absence of a car is the primary initiator of safety, freedom and comfort for users (Stanojlovic, 2016: 31). The organization of contrasting places in space influences the dynamic and pedestrian potential (Reba, 2010: 48), which is significant for the recognition and actuality of a place.

According to Jan Gehl (Gehl, 2011: 62), physical arrangement can promote or prevent visual and auditory contact in at least five different ways:

A. Inhibiting contact: walls long, distances, high speeds, multiple levels, back-to-back orientation;

B. Promoting contact: no walls, short distances, low speeds, one level, face-to-face orientation. 


\section{METHODOLOGICAL APPROACH TO THE RESEARCH}

Introduction of new methodologies in public life studies that are based on mathematical models can be used to "process data in order to predict where people will probably go and which way they will probably take and how often they will take it" (Gehl and Svarre, 2013: 75). This paper studies link between spatial aspects of built environment and movement/visibility at the public space through space syntax methodology. Space syntax is based on theory of spatial configuration, introduced by Bill Hillier, theoretical framework that is "capturing the inner logic of at least some aspects of the form and functioning of built environments" (Hillier, 2007 [1996]: 1). Space syntax is used as method in order to study the movement of people, patterns of their movement, most probable routes, visual integration at public space, etc. Data is analysed through visibility graph analysis (VGA), a space syntax technique for quantifying visibility relations between different points in the public space.

The specific focus of this paper is on visual integration and connectivity, two parameters that have important role in visual perception at public space, and furthermore vitally effect pedestrian mobility. Visual integration can be defined as "potential area in the layout where one can see much of the layout and can be easily seen" (Al Sayed, et al., 2014: 37). It has a significant role in wayfinding, navigation, as well as in decision-making considering direction of movement, etc. Connectivity indicates the number of elements each element is directly connected to (Ibid.: 19). This measure of the number of immediate spaces that are directly connected to the observed space can influence pedestrian accessibility, permeability and mobility at open public spaces of the city.

Multi-layered analysis in this paper are done in a software platform DepthmapX, which studies a spatial network in order to better understand social processes within a built environment (Varoudis, 2012). Model of public space which is used in analysis is based on representation of selected fragment of urban structure as arrangement of opened spaces (e.g. streets, squares, etc.) and closed spaces (e.g. buildings and other structures), whereas open spaces are commonly represented in lighter colour and surrounding buildings are represented in darker colour. Software constructs a coloured visibility graph that determines degree of visibility, and indicates which areas have a strong visual link between them, and which ones are visually isolated.

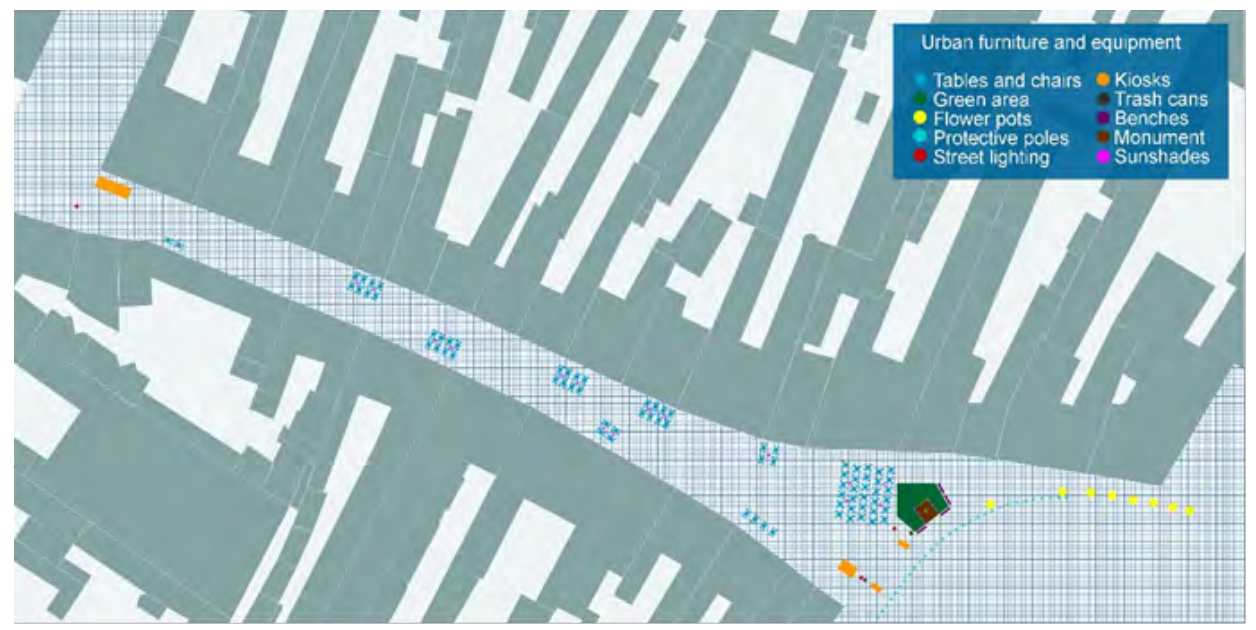

_ Figure 1: Spatial layout of Dunavska Street in Novi Sad divided into a square network which is covering visible and accessible areas of the street. Drawing shows open public spaces (lighter colour), closed spaces such are buildings (darker colour) and all observed street furniture and equipment. (source: Stefan Škorić)

In order to create the visibility graph, a CAD drawing of chosen public space intended for analysis 
has to be divided into a network of equal squares (generally in size of human step), which are covering publicly visible and accessible areas (Figure 1). In the next step of analysis, the inter-visibility is determined between the central point of each unit (i.e. the square of the network) with all other units within a selected area for analysis. The edges of the graph are then made between any two units if those two units are mutually visible. Visibility graph represents all accessible routes and areas of public space in red tones, and all locations that are segregated, difficult to reach and with low visibility in blue tones.

\section{CASE STUDY: DUNAVSKA STREET}

The Dunavska Street (or Danube Street) represents one of the most visited pedestrian streets of Novi Sad (Serbia). It is an important fragment of the pedestrian zone in the protected old town centre (Figure 2), with many historic and cultural monuments of the city. A car-free pedestrian zone of the city was developed in the 1980s, in contrary to construction of new boulevards and other vehicular infrastructure of the city. Up to today, it has been used as one of the most frequent pedestrian routes, administrative and shopping centre, as well as for the gatherings of a large number of people (demonstrations, music concerts, etc.) and for organization of various events in the open (film festivals, open-air exhibitions, etc.).
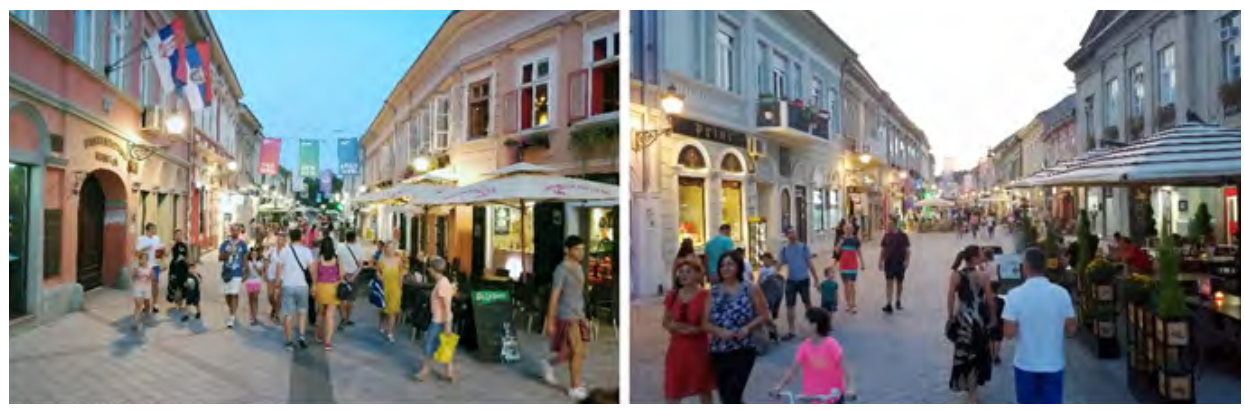

_ Figure 2: Dunavska Street today - touristic, admistrative, shoping and social centre of Novi Sad and main pedestrian walkway of the city. (source: Aleksandra Milinković)

Even though the street is without any immense visual or physical obstacles that could significantly disrupt movement and visibility of pedestrians, arrangement of moveable furniture of cafes and restaurants has induced great negative effect on the pedestrian permeability. Therefore, this paper explores spatial parameters that are determining visibility and mobility relations within Dunavska Street. The study is done in order to understand how are all spaces physically and visually connected within the selected street, and how such relations can positively affect or limit pedestrian movement and visibility.

Dunavska Street is linear route divided into pedestrian part and part of the street intended for motor traffic which was not included in analysis. Pedestrian part of the street can be divided into three fragments - intersection with Zmaj Jovina Street and Gimnazijska Street (1), middle part of Dunavska Street (2), and inflow into Ignjata Pavlasa Street and other part of Dunavska Street intended for motor traffic (3). Three fragments of the street vary in functional and morphological characteristics important for analysis (Table 1), particularly in the width of the cross section going from 7,5m in narrowest part of fragment (2), to $30 \mathrm{~m}$ in widest portion of fragment (3). Most of the surrounding buildings have two floors, with different uses and ground floor contents such are commercial (restaurants, cafes, bank, shops, etc.), public (library, museum, etc.), etc.

The visibility graph analysis was done on prepared a CAD drawing of Dunavska Street that was divided into a network of equal squares $(100 \mathrm{~cm} \times 100 \mathrm{~cm})$. The visibility relations were determined be- 
tween the central points of each unit of proposed grid with all others. The analysis was done on two levels - analyses of connectivity at the ground level with the focus on pedestrian permeability and mobility, and at the eye level with the focus on visual integration, both with and without the observed obstacles. The focus of permeability analysis was on physical obstacles that could induce changes primarily in the pedestrian movement such are moveable furniture of outdoor cafes and restaurants, flower pots, street lighting, trash cans, benches, kiosks, and other elements of public furniture and equipment. Observed obstacles have mostly effected pedestrian mobility, and in most of the cases didn't represent significant visual obstacles.

_ Table 1: Characteristics of the pedestrian part of the Dunavska Street and satellite image with three fragments pointed out (source: https://geosrbija.rs/)

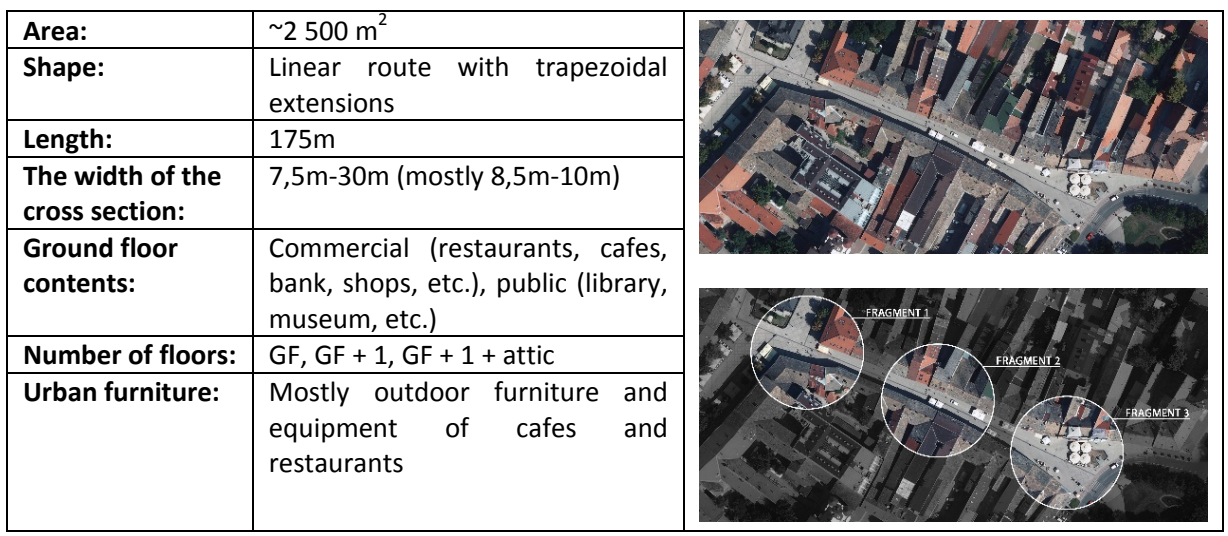
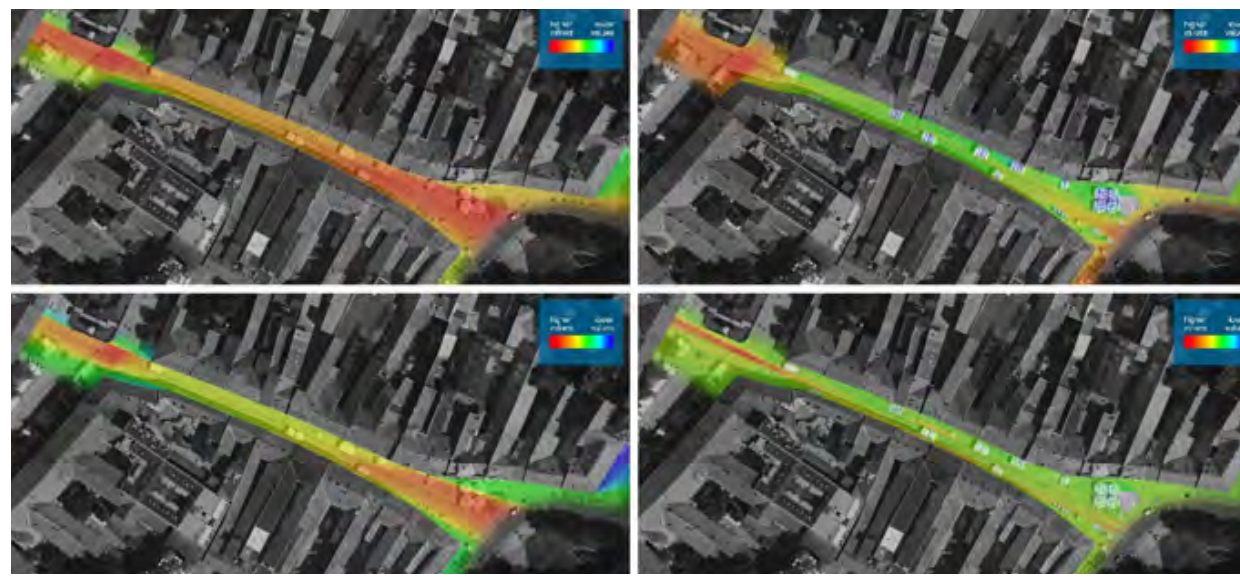

_ Figure 3: Visibility graph analysis of visual integration at eye level without the obstacles (up, left) and with the obstacles (up, right); connectivity at ground level without the obstacles (down, left) and with the obstacles (down, right). (source: Stefan Škorić)

The analysis of visual integration at the eye level without the observed obstacles (Figure 3, up, left), indicates high results in almost every fragment of the street, with focus on fragments (1) and (3). When observed obstacles are taken into analysis (Figure 3, up, right), fragment (2) shows drastically lower values than other two fragments. The width of the street and the shape of its inflow into surrounding streets have left observers with much wider viewing fields, covering most of its surrounding at fragments (1) and (3). Although it is part of the old town, pedestrian part of Dunavska Street 
is nearly clear linear route, which enables high values of visual integration on all parts of its entity. Almost all points of space have high values of connectivity at ground level without the obstacles (Figure 3, down, left), showing good connection between different parts of the street. The study showed that observed obstacles had greater negative effect on mobility than it had on visibility at eye level (Figure 3, down, right). Unregulated placement of moveable furniture of café bars creates unclear pedestrian routes, constraining pedestrians from walking in strait line. Positive aspects of spatial layout at fragment (1) and (3) such are size, shape and width, were annulled by obstacles that were in some occasions placed directly on potentially most natural and logical walking routes. Although it has shown the highest value of visual integration, fragment (3) showed lowest values of connectivity at ground level where most of the outdoor cafes and restaurants, kiosks, and other elements of public furniture and equipment were grouped.

Lack of denivelation of space, walls, larger structures, or any other greater visual obstacles, showed that outdoor furniture and equipment do not induce greater effect on the users' visibility. Both analysis had showed that alongside existing obstacles, a spatial configuration of the street, and especially its width, had played role in low values of visual integration in the middle part of the street distinguished as fragment (2). Placement of moveable furniture of café bars in combination with spatial configuration of the narrowest middle part of street had a negative effect on free movement and on limitation of viewing fields.

\section{CONCLUSIONS}

Good visibility relations between different points in open public space create affirmative preconditions for social interaction of users involved in various public activities taking place on public spaces of city. It has been observed that people prefer areas with the major visual integration of space, and which is offering them widest possible field of vision overlooking the public space. On the other hand, the visual isolation and exclusion of certain points of public space generates parts of public space that pedestrians are not likely going to use. In such sense, enhancement of visibility relations can possibly expand probabilities for new encounters and social activities amongst diverse groups of users engaged in public activities on open public spaces of the city.

Public furniture and equipment can partially obstruct or even completely limit pedestrian mobility on public space, particularly if their positioning is not in line with most frequent pedestrian routes and paths. Preconditions for a pleasant walk throughout the city is undisturbed movement without interruptions and impediments. Therefore, special emphasis has to be put on legal regulations envisioned for placement of furniture and equipment, particularly of private cafes and restaurants that are disturbing free movement. Gehl (2011: 133) introduces a measure of "room to walk" defined as the human level of tolerance for interferences encountered during walking. Therefore, adequate design and positioning of urban furniture and equipment could considerably improve mobility on public space by offering pedestrians with variety of undisrupted walking routes.

Study and understanding of visual integration of the built environment and its open public spaces, might be used in evaluation and prediction of the pedestrian movement, and patterns of their movement. Additional direct observation would be necessary to furthermore explore the relations of visibility and mobility with the spatial configuration of built environment. Research on broader selection of public spaces in Novi Sad, could generate input for creation of new model for designing and planning of new public spaces, and for the assessment or reconstruction of the existing public spaces of the city. 


\section{ACKNOWLEDGEMENTS}

This research (paper) has been supported by the Ministry of Education, Science and Technological Development through the project no. 451-03-68/2020-14/200156: "Innovative scientific and artistic research from the FTS (activity) domain".

\section{REFERENCES}

_- Al Sayed, Kinda, and Alasdair Turner, Bill Hillier, Shinichi lida, and Alan Penn. 2014. Space Syntax Methodology. London: Bartlett School of Architecture, UCL.

_- Đukić, Aleksandra, and Milena Vukmirović. 2011. "Walking as a Climate Friendly Transportation Mode in Urban Environment (Case study: Belgrade)." International Journal for Traffic and Transport Engineering, vol. 1(4): 214-230.

- Ellin, Nan. 2006. Integral Urbanism. London: Routledge.

- Gehl, Jan, and Birgitte Svarre. 2013. How to study public life. Washington: Island Press.

_ Gehl, Jan. 2010. Cities for people. Washington: Island Press.

- Gehl, Jan. 2011. Life between Buildings: Using Public Space. Washington: Island Press.

_- Goffman, Erving. 1966. Behavior in Public Places - notes on the social organization of gatherings. New York: The Free Press.

_- Hillier, Bill. 2007 [1996]. Space is the machine - A configurational theory of architecture. London: Space Syntax.

_- Milinković, Aleksandra. 2019. Reperne i žižne tačke kao elementi fizičke structure vojvođanskih naselja

- doktorska disertacija, Novi Sad: Fakultet tehničkih nauka.

- Montgomery, John. 1998. "Making a city: Urbanity, vitality and urban design." Journal of Urban Design, vol. 3, no. 1: 93-116.

- Montgomery, John. 2007. The New Wealth of Cities: City Dynamics and the Fifth Wave. London: Ashgate.

- Reba, Darko. 2010. Ulica - Element strukture i identiteta. Beograd: Orion art.

- Škorić, Stefan, and Milena Krklješ, Dijana Brkljač, and Aleksandra Milinković. 2016. The Image, Transformations and Permanence of Republic Square. Conference Proceedings of the 3rd International Academic Conference on Places and Technologies, 14th-15th April 2016, Belgrade: Faculty of Architecture, University of Belgrade: 473-479.

- Speck, Jeff. 2013. Walkable City. New York: North Point Press.

- Stanojlović, Aleksandar. 2016. Pešačke zone u starim gradskim jezgrima. Petrovaradin: Pokrajinski zavod za zaštitu spomenika kulture.

- Stupar, Aleksandra. 2009. Grad globalizacije - Izazovi, transformacije, simboli. Beograd: Arhitektonski fakultet Univerziteta u Beogradu, Orion art.

- Varoudis, Tasos. 2012. DepthmapX - Multi-platform Spatial Network Analyses Software. Accessed January 10, 2020. https://github.com/varoudis/depthmapX

- Whyte, William H. 1980. The Social Life of Small Urban Spaces. New York: Project for Public Spaces. 